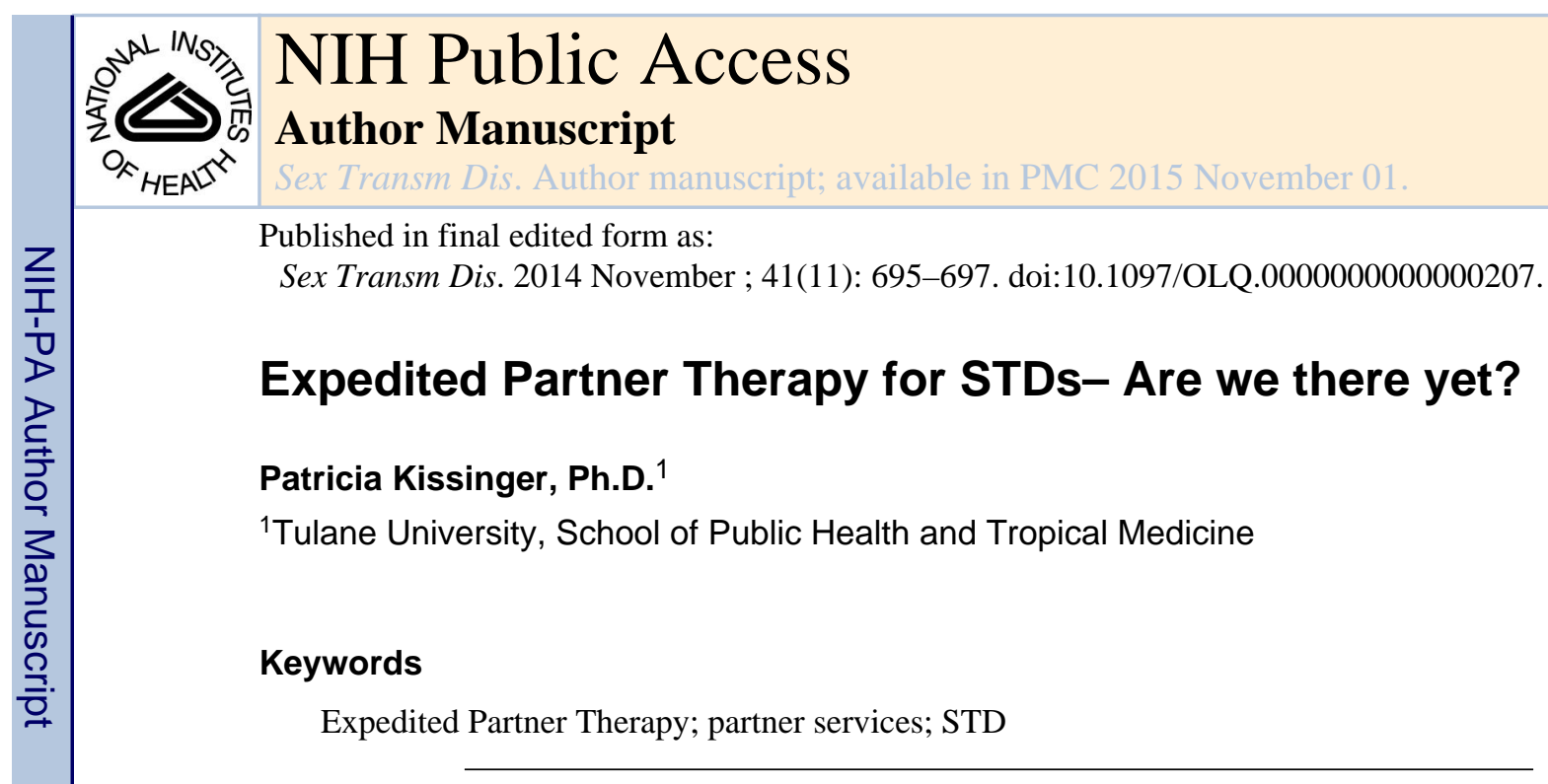

Repeat STIs cause a significant amount of reproductive morbidity and an important percentage of repeat infections are caused by re-infection from untreated sex partners. ${ }^{1}$ Expedited partner therapy (EPT), or the provision of medicine to a sex partner of a persons infected with an STI without the requirement of a clinical exam, was conceived to accelerate and facilitate partner treatment, thus reducing the chance of re-infection to the index person. EPT was endorsed by the Centers for Disease Control and Prevention (CDC) in 2006 as a useful option for partner management for selected STDs among heterosexuals. To date, at least 26 RCTs have been conducted to evaluate EPT. A recent meta-analysis of these RCTs found that EPT reduced repeat infections by 20-29\% depending on the STD and the demographics of the index person and resulted in more partners being treated when compared to standard partner referral by the index patient. ${ }^{2}$ So there is good evidence that, in randomized trials, EPT is efficacious for reducing repeat STIs.

In this edition of Sexually Transmitted Diseases, Vaidya et al. evaluated acceptance of patient-delivered partner therapy (PDPT), a form of EPT, in New York City STD clinics. ${ }^{3}$ Their findings were highly encouraging, in that, under the best circumstances (i.e. when legal, with funding, when offered by the provider) half of eligible index patients accept PDPT to bring to their sex partners. And for the majority of those who don't accept, their reason for not accepting was that either their partner had already been treated or the partner was no longer accessible to the index person. So in essence, most partners who could or should get EPT, likely got it. This adds to the growing literature indicating that index patients will accept EPT if offered. ${ }^{4-6}$

The situation in NYC is a great model for how EPT could work. Unfortunately, in many parts of the U.S., EPT is still not widely used because of barriers that are further upstream in the EPT cascade such as legality, funding, policy and provider reticence. The cascade depicted in Figure 1 shows the steps that are needed for the partner to actually get treated via EPT. These steps are discussed below.

\title{
Legalization
}

For several years, CDC has offered guidance on how to seek legalization of $\mathrm{EPT}^{7}$ and been tracking the legal status of EPT in the states. ${ }^{8}$ As of August, 2014, EPT, specified usually for chlamydia and gonorrhea and generally for heterosexuals, was legal in 35 states and 
illegal in only 6 . So the legal barrier continues to deteriorate and it appears that legalizing EPT in all states is a winnable battle. A recent study by Cramer et al. ${ }^{9}$ found that if EPT was legal, providers were almost 2.5 times more likely to offer it, yet only $9.5 \%$ of interviewed patients with gonorrhea reported receiving EPT for their partners. EPT legality is, therefore, a necessary but not sufficient criterion for uptake.

\section{Funding available}

Funding for EPT is dependent on state laws and health care agency policies that permit funding. These policies may be more driven by competing priorities than the cost effectiveness of the intervention. EPT has been shown to be cost effective if both the index and the partners are receiving care from the same agency. ${ }^{10}$ This is likely to be the case when the partners are married or when both are on Medicaid, however may not be the case in the remaining situations. EPT in the form of PDPT means that the clinic has to have the medication available at the clinic. In New York, where $80 \%$ of the Federally Qualified Health Centers (FQHCs) have policies allowing or promoting EPT, and funding available, many partners receive EPT. However, in Louisiana and other states in the STD-belt, where the largest Medicaid providers do not have policies or funds to provide EPT, the minority of partners receive EPT. In Washington state, where the low cost federal program pricing (i.e. $340 \mathrm{~b}$ ) was allowed for EPT, the cost of treating partners was $\$ 8.75 .{ }^{11}$ Since the cost of an untreated chlamydia infection ranges from $\$ 244$ in direct costs ${ }^{12}$ and $\$ 130$ in productivity loss, ${ }^{13}$ this is a large cost savings. Unfortunately, cost decisions are often made in response to the immediate need rather than in the long view. Advocacy in the state legislatures and at private insurance companies is needed to make funding for EPT available thus ensuring the next step in the uptake of EPT.

\section{Providers offer}

In a study conducted nearly a decade ago, only half of providers surveyed ever gave EPT to their patients and far fewer offered it regularly to their patients with STDs. ${ }^{14}$ While no recent statewide estimates are available, ad hoc studies have shown high provider acceptance when funding was available, when the index case was a woman, and when administration supported it. ${ }^{13}$ Concerns about liability, lost opportunities for partner counseling and evaluation, time requirements for index counseling and funding need to be addressed. Requiring documentation of EPT in medical records, as was done in Colorado, can improve provider uptake of EPT in an environment where EPT is both legal and funded. ${ }^{4}$ Where policies by professional organizations supporting EPT exist, providers are more likely to use it. ${ }^{9}$ Favorable policies, professional endorsement, legal status and funding are needed to persuade many providers to offer EPT.

\section{Index accepts}

Hypothetical acceptance of EPT was high among adolescents (85\%) in one study. ${ }^{15}$ When offered, acceptance rates among heterosexuals have ranged from $44 \%$ in San Francisco ${ }^{5}$, to $35 \%$ in Denver, ${ }^{4}$ to $55 \%$ in New York. ${ }^{3}$ There does not appear to be a single profile of what type of index person will accept EPT when offered, given the lack of consistency between the studies that have examined factors associated with patient acceptance. ${ }^{3-5}$ Partnership 
characteristics may be more influential in that if the partnership is of longer duration, the partner is considered a main partner, and if the index patient thinks they the couple will reinitiate sex, EPT is more likely to be given. ${ }^{16,17}$ EPT should be a patient-provider decision.

\section{Partner takes}

Because most studies have focused on the index person, data from partners offered EPT has not been available. However, studies that have documented the index case's perception of the partner's compliance with EPT, consistently show acceptance rates $>70 \%{ }^{6} \mathrm{~A}$ qualitative study found more positive perceptions than negative perceptions regarding EPT among persons representative of partners given EPT, but that proper packaging was necessary. ${ }^{18}$ More research is needed from the perspective of the partner.

Other issues that arise are logistical. For example, many persons infected with STDs are treated presumptively (i.e. based on symptoms or situation before test results are available), and policy often prohibits treatment of partners unless an organism is present. Furthermore, asymptomatic persons who are screened and don't come back for their results also do not benefit from EPT. In the absence of a point-of-care test for chlamydia, this trend is likely to continue.

In lieu of PDPT, some providers offer EPT in the form of prescriptions. While this is potentially better than partner referral alone, if the partner doesn't have insurance or transportation or has other barriers to accessing the medication, it is unlikely that the prescription will be filled. The Affordable Care Act is designed to reduce the insurance barrier. In 2014, only $15.9 \%$ of American still did not have insurance, ${ }^{19}$ but how many of these plans would cover EPT is not known.

In summary, legal barriers are rapidly dissolving and it appears that patient and partners, when offered, will accept EPT. Funding mechanisms and policies remain as important barriers to making EPT available. Without funding, the drugs will not be available to offer and without policies to protect health care providers from liability, providers will remain cautious about using EPT. CDC could take a lead in this role as they did with legal assistance for EPT.

So are we there yet? Nearly 10 years since the recommendations for EPT use was made by $\mathrm{CDC}$, we are coming along, but more translational research and advocacy are still needed to make EPT available to all who need it.

\section{References}

1. Kissinger PJ, Reilly K, Taylor SN, Leichliter JS, Rosenthal S, Martin DH. Early repeat Chlamydia trachomatis and Neisseria gonorrhoeae infections among heterosexual men. Sex Transm Dis. 2009 Aug; 36(8):498-500. [PubMed: 19617870]

2. Ferreira A, Young T, Mathews C, Zunza M, Low N. Strategies for partner notification for sexually transmitted infections, including HIV. Cochrane Database Syst Rev. 2013; 10:CD002843. [PubMed: 24092529]

3. Vaidya S, Johnson K, Rogers M, Nash D, Schillinger J. Predictors of index patient acceptance of expedited partner treatment for Chlamydia trachomatis infection, and reasons for refusal, sexually transmitted disease clinics, New York City, 2011-2012. Sex transm Dis. 2014 
4. Mickiewicz T, Al-Tayyib A, Thrun M, Rietmeijer C. Implementation and effectiveness of an expedited partner therapy program in an urban clinic. Sex Transm Dis. 2012 Dec; 39(12):923-929. [PubMed: 23169171]

5. Kerns JL, Jones HE, Pressman EJ, Fratarelli LA, Garth J, Westhoff CL. Implementation of expedited partner therapy among women with chlamydia infection at an urban family planning clinic. Sex Transm Dis. 2011 Aug; 38(8):722-726. [PubMed: 21844724]

6. Handsfield, H.; Hogben, M.; Schillinger, J.; Golden, M.; Kissinger, P.; Sparling, F. EXPEDITED PARTNER THERAPY IN THE MANAGEMENT OF SEXUALLY TRANSMITTED DISEASES. In: Prevention CfDCa. , editor. 2006.

7. Centers for Disease Control and P. Legal/Policy Toolkit for Adoption and Implementation of Expedited Partner Therapy. 2011. http://www.cdc.gov/std/ept/legal/EPT-toolkit-complete.pdf.

8. Centers for Disease Control and P. Expedited Partner Therapy. http://www.cdc.gov/std/ept/ default.htm.

9. Cramer R, Leichliter JS, Stenger MR, Loosier PS, Slive L. Group SSW. The legal aspects of expedited partner therapy practice: do state laws and policies really matter? Sex Transm Dis. 2013 Aug; 40(8):657-662. [PubMed: 23859917]

10. Gift TL, Kissinger P, Mohammed H, Leichliter JS, Hogben M, Golden MR. The cost and costeffectiveness of expedited partner therapy compared with standard partner referral for the treatment of chlamydia or gonorrhea. Sex Transm Dis. 2011 Nov; 38(11):1067-1073. [PubMed: 21992986]

11. Golden MR, Hogbe M, Levine MA. Ethics of expedited partner therapy. Virtual Mentor. 2008; 10(11):708-718. [PubMed: 23211884]

12. Chesson HW, Blandford JM, Gift TL, Tao G, Irwin KL. The estimated direct medical cost of sexually transmitted diseases among American youth, 2000. Perspectives on sexual and reproductive health. 2004 Jan-Feb;36(1):11-19. [PubMed: 14982672]

13. Blandford JM, Gift TL. Productivity losses attributable to untreated chlamydial infection and associated pelvic inflammatory disease in reproductive-aged women. Sex Transm Dis. 2006 Oct; 33(10 Suppl):S117-S121. [PubMed: 17003678]

14. Hogben M, McCree DH, Golden MR. Patient-delivered partner therapy for sexually transmitted diseases as practiced by U.S. physicians. Sex Transm Dis. 2005 Feb; 32(2):101-105. [PubMed: 15668616]

15. Radovic A, Burstein GR, Marshal MP, Murray PJ, Miller E, Sucato GS. Adolescents' attitudes toward expedited partner therapy for sexually transmitted infections. Sex Transm Dis. 2013 Nov; 40(11):894-897. [PubMed: 24113416]

16. Gursahaney PR, Jeong K, Dixon BW, Wiesenfeld HC. Partner notification of sexually transmitted diseases: practices and preferences. Sex Transm Dis. 2011 Sep; 38(9):821-827. [PubMed: 21844737]

17. Kissinger P, Mohammed H, Richardson-Alston G, et al. Patient-delivered partner treatment for male urethritis: a randomized, controlled trial. Clinical infectious diseases : an official publication of the Infectious Diseases Society of America. 2005 Sep 1; 41(5):623-629. [PubMed: 16080084]

18. McBride K, Goldsworthy RC, Fortenberry JD. Formative design and evaluation of patientdelivered partner therapy informational materials and packaging. Sexually transmitted infections. 2009 Apr; 85(2):150-155. [PubMed: 19103640]

19. Poll, G. U.S. Uninsured Rate Continues to Fall. 2014. http://www.gallup.com/poll/167798/ uninsured-rate-continues-fall.aspx. 


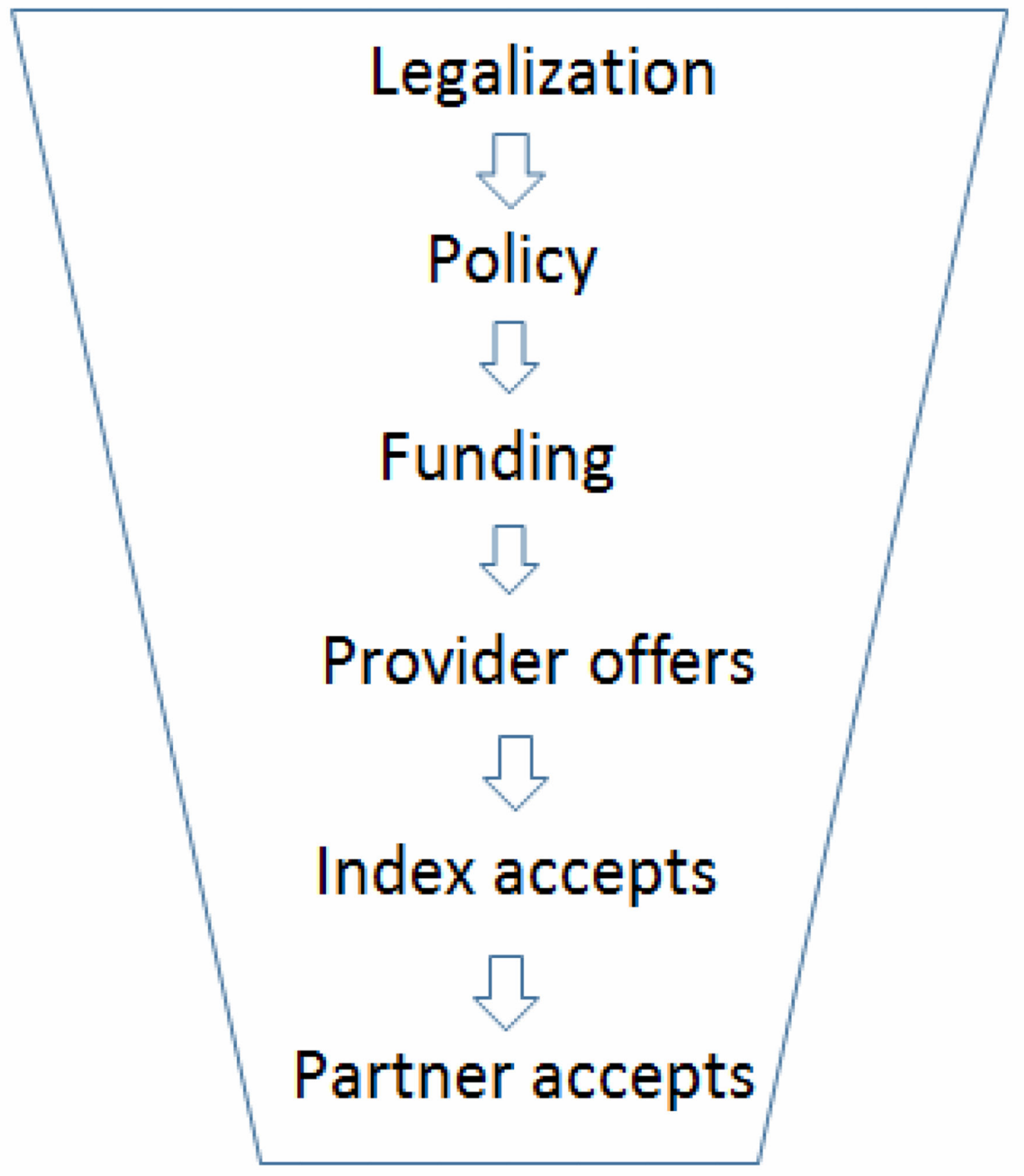

Figure 1.

EPT cascade 